\title{
Numerical and Experimental Study of a Novel Valve Using the Return Stream Energy to Adjust the Speed of a Hydraulic Actuator
}

\author{
Grzegorz Filo ${ }^{1,}{ }^{*}$ - Edward Lisowski ${ }^{1}$ - Dominik Kwiatkowski ${ }^{1}$ - Janusz Rajda ${ }^{2}$ \\ ${ }^{1}$ Cracow University of Technology, Poland \\ 2 PONAR Wadowice, Poland
}

This article discusses the possibility of increasing the speed of movement of a single-sided hydraulic cylinder piston rod using a fluid stream from the return line. Directing the return stream back to the supply line instead of the fluid reservoir causes significant increase in the inflow rate to the actuator. This situation may arise when the piston rod of the cylinder is not fully loaded on part of the movement range. As part of this work, we proposed a solution in the form of a novel control valve, consisting of a throttle valve and a differential valve controlled by the pressure difference between the supply line and the return line. A geometric model was created using SolidWorks, then a simulation model was made in Matlab/Simulink. Next, simulations were carried out to prove that the use of the return fluid stream gives a possibility of a significant increase in the piston rod speed. The results of the numerical analyses were verified on a test bench where the valve prototype was tested. Speed characteristics of the piston rod against both payload force and throttle valve setting were determined. High convergence with the simulation results was obtained. It has also been confirmed that the proposed solution can be advantageous in practical applications. Keywords: hydraulic system modelling, return stream energy usage, novel control valve design, hydraulic actuator speed adjustment

Highlights

- $\quad$ Adjusting the speed of a hydraulic actuator piston rod movement depending on the payload.

- Using the energy of a return fluid stream to re-supply a hydraulic actuator.

- Modelling, carrying out simulations in Matlab/Simulink, and conducting experiments on a test bench.

- Obtaining a wide range of hydraulic actuator speed changes and achieving a high level of convergence of simulation results and experimental tests.

\section{INTRODUCTION}

Hydraulic cylinders are commonly used as actuators in drive systems. Their main advantage is the ability to operate with large forces, while having small dimensions and relatively simple installation. Both fixed and variable capacity pumps can be used to supply hydraulic cylinders. In general, variable capacity pumps provide better power management and speed control, but they are more expensive and require dedicated electronic controllers. In the case of constant-capacity pumps, the actuator speed can be controlled hydraulically, using the system of control valves. Usually, flow regulators or throttle valves are used for this purpose.

The adjustment of a hydraulic actuator speed that depends on the payload value allows the working time to be shortened as well as the efficiency of the fluid stream energy conversion to mechanical energy to be improved. This subject has been undertaken in numerous scientific publications, and several different ways to solve it can be found. One group of solutions is based on the use of a variable displacement pump and proportional control valves with sensors, transducers, and a digital controller. A two-level idle speed control system with a hydraulic accumulator for an excavator was proposed by Lin et al. [1] to reduce energy consumption and improve the control performance of the actuator when the idle speed control is switched off. Experimental results showed high energy efficiency and excellent control performance of the automatic switching system between the first idle speed, the second idle speed, and the normal operating speed of a hydraulic cylinder. Pérez et al. [2] presented a robust controller for the hydraulic actuator force control, while Wang et al. [3] proposed a novel position-pressure master-slave controller for the hydraulic servo system. Moreover, Wang and Wang [4] developed an energy-saving control strategy with a load-sensing structure including a load-sensing pump, a proportional relief valve, a throttle valve, and an adaptive control algorithm.

The second group includes solutions based on the appropriate configuration of hydraulic control valves, without the use of advanced digital controllers. Liu et al. [5] showed a direct proportional flow control system with a load pressure compensation feature on a load control valve. The proposed solution provides 
a flow through the control valve to be proportional to the pilot pressure in the control stroke and thus decides the overrunning load lowering speed control performance of the whole system. A novel method of design for hydraulic robotic lifting equipment was designed by Adeoye et al. [6]. The method involves the use of a flow control valve and a pressure relief valve for stroke speed adjustment of a lifting device with a hydraulic cylinder. Another design example of a pilot-assisted load control valve for proportional flow control based on dynamics modelling was presented by Xie et al. [7]. The flow through the designed valve is proportionally controlled by pilot pressure. The static and dynamic flow control performance of the valve has been validated by the tests made in a mobile crane lifting and lowering system. Similarly, Man et al. [8] proposed an energy regeneration system with the accumulator that can reduce the energy consumption of hydraulic impulse testing equipment by $15 \%$.

This article discusses the possibility of increasing the speed of movement of a single-sided hydraulic cylinder using a fluid stream from the return line. Usually, a fluid stream in the return line is not used, since it goes straight to the reservoir. On the other side, directing the return stream to the supply line instead of the fluid reservoir causes a significant increase in the inflow rate to the actuator. This situation may arise only when the piston rod of the cylinder is not fully loaded on the part of its movement range. However, it occurs quite often in practice, e.g., in the hydraulic system of a press for garbage compression, an extruder, a cutter, a squeezer, etc. The use of the return fluid stream gives a possibility of an increase in a piston rod speed of movement even by several times, depending on the hydraulic cylinder geometry (ratio of cylinder and rod diameters) as well as the range of the movement in which the cylinder is not fully loaded. According to the presented literature analysis, such a system requires the use of appropriate control, which may be electronic or hydraulic. In general, hydraulic control is less expensive and easier to apply, since it does not require transducers or microprocessor chips; however, it is less accurate. Hence, a solution in the form of a novel control valve has been proposed. The valve consists of a throttle valve and a differential valve controlled by the pressure difference between the supply line and the return line. Simulations were carried out to prove that the use of the return fluid stream gives the possibility of even a threefold increase in the piston rod speed of movement. The results of the numerical analyses were then verified on a test bench where the valve prototype was tested. Speed characteristics of the piston rod as a function of both payload and throttle valve setting were obtained, achieving a high level of convergence with the simulation results. It has also been confirmed that the proposed solution is accurate enough and can be an advantageous option in practical applications.

\section{WORKING PRINCIPLE OF ANALYSED VALVE}

A flow control valve UZFD6 shown in Fig. 1 is the subject of the analysis. The valve consists of a monolithic block inside of which flow paths have been hollowed out. Also, a differential valve (3) and two throttle check valves (1), (2) have been placed in the block.

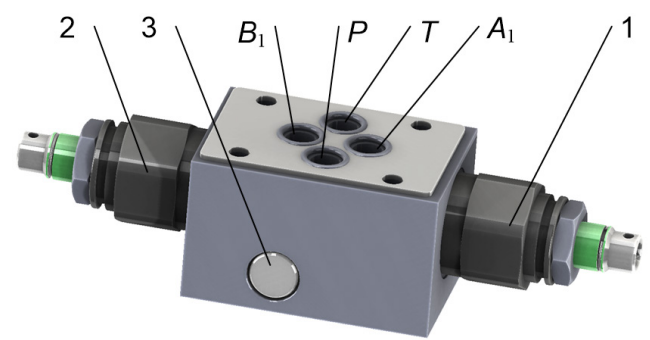

Fig. 1. Flow control valve UZFD6: (1) throttle valve on the supply side $s$, (2) throttle valve on the load side $t$, (3) differential valve;

$A_{1}, B_{1}$ connection channels; $P$ supply port; $T$ return port

The valve is adapted for a direct connection to the electrically controlled WE6-type control valve. For this purpose, appropriate $P, T, A_{1}, B_{1}$ connection channels have been made on both sides of the valve body. A cross-section through the differential valve is presented in Fig. 2. As seen in the figure, a one-stage poppet valve has been applied. Flow through the valve occurs when the hydrostatic force coming from the $p_{t}$ pressure exceeds the sum of the hydrostatic force coming from the $p_{s}$ pressure and the initial $F_{s 3}$ spring tension.

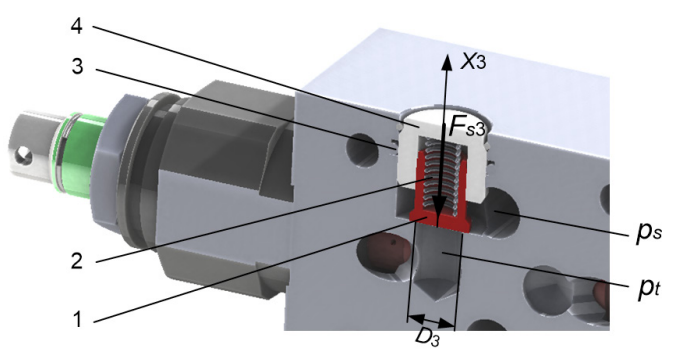

Fig. 2. Sectional view of the differential valve: (1) poppet,

(2) spring, (3) sealing, (4) cover; $x_{3}$ axis of poppet movement

The throttle valve located on the supply side was not included in the model or the research. It was set in 
an open position during all laboratory tests. In contrast, the throttle valve located on the load side played an important role in obtaining the characteristics. A sectional view of this valve is shown in Fig. 3.

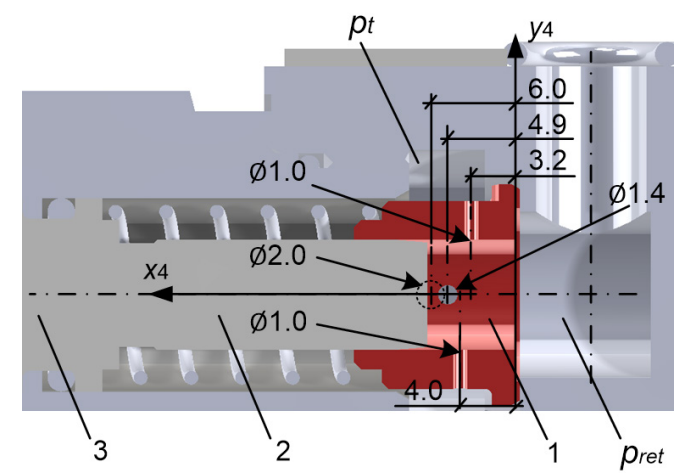

Fig. 3. Sectional view of a throttle valve located on the load side: (1) sleeve, (2) pin, (3) knob; $p_{t}$, $p_{\text {ret }}$ pressures; $x_{4}$ axis of pin movement

A throttling gap is formed by four holes of various diameters drilled in the collar of the sleeve (1). A pin (2) can move inside the sleeve, gradually revealing the holes. The position of the pin, and thus the throttling gap area, can be set by the operator using a knob (3). The $A_{4}$ gap area has been calculated as a function of the $x_{4}$ pin position with regard to the diameters and positions of the holes. A graph of the obtained function is shown in Fig. 4.

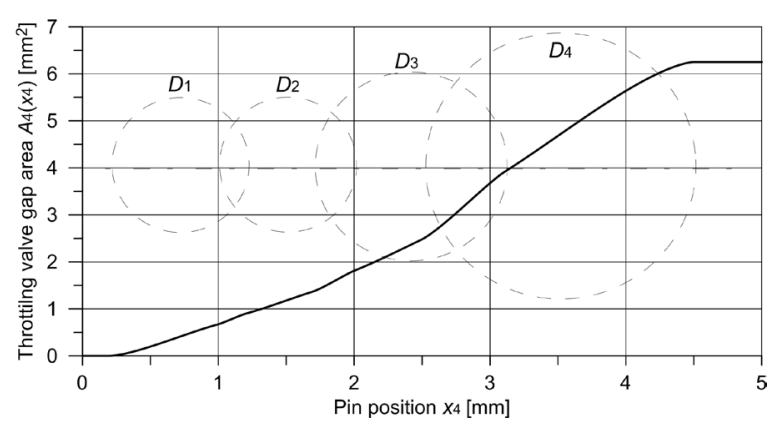

Fig. 4. Throttling gap area against the pin position

\section{MODEL OF THE SYSTEM}

In the first stage, a mathematical model of the system was formulated using equations of movable element motion, flow equations through gaps, balances in the separated volumes and geometric relationships. Next, a simulation model was built by introducing the obtained equations to the Matlab-Simulink system.

\subsection{Formulating a Mathematical Model}

A mathematical model of the system was built according to a numerical modelling methodology, which was first proposed by Watton and Nelson [9], and then used by Naseradinmousavi and Nataraj [10] and Casoli et al. [11] among others. It comprises equations of motion, flow balances of isolated volumes, flow equations through throttle gaps and orifices, and geometrical equations. A schematic of the modelled system is shown in Fig. 5. The model takes into account the case of supplying the hydraulic actuator on the side without the piston rod. Thus, the rod slides out from the cylinder. Without the flow through the differential valve $\left(Q_{3}=0\right)$, theoretical speed can be easily calculated from Eq. (1). Moreover, in this case, the speed in the opposite direction is higher, since the active cylinder area is reduced by the rod area.

$$
v_{c y l}=\frac{4 \cdot Q_{1}}{\pi \cdot D_{c y l 1}^{2}}, \text { where } Q_{1}=Q_{p}-Q_{5} .
$$

In a system with a differential valve, which directs the return stream from the actuator back to the supply line, it is possible to significantly vary the speed of the piston rod, using the same fixed-speed pump. The obtained speed of the rod may be lower, equal to or higher than the return movement speed. However, the calculation of the piston speed is now far more complex, since the flow rate $Q_{1}=Q_{\mathrm{p}}-Q_{5}+Q_{3}$, where $Q_{3}$ depends on the payload and the throttle valve settings. The next paragraphs present the process of a mathematical model formulating.

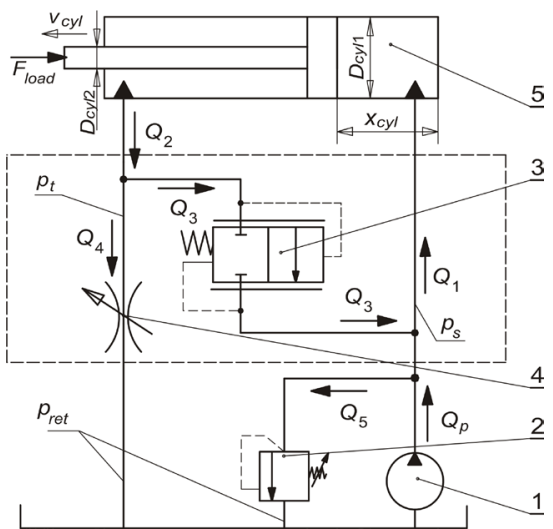

Fig. 5. Schematic of the modelled hydraulic system: (1) pump, (2) relief valve, (3) differential valve, (4) throttle valve, (5) hydraulic cylinder; $p_{s}, p_{t}, p_{\text {ret }}$ pressures; $Q_{p}, Q_{1}, \ldots, Q_{5}$ flow rates, $F_{\text {load }}$ payload of the actuator 
The input function is a $Q_{p}$ volumetric flow rate generated by the pump. The flow rate value is assumed to be constant except the $t_{\text {start }}$ start-up time, when it increases linearly.

$$
Q_{p}= \begin{cases}Q_{p_{-} \text {nom }} \cdot \frac{t}{t_{\text {start }}}, & \text { if } t<t_{\text {start }} \\ Q_{p_{-} \text {nom, }} & \text { otherwise. }\end{cases}
$$

The flow balance of the supply line is used to calculate the supply pressure:

$$
\frac{d p_{s}}{d t}=\frac{\beta}{V_{s}+A_{c y l 1} \cdot x_{c y l}} \cdot\left(Q_{p}-Q_{1}+Q_{3}-Q_{5}\right) .
$$

Similarly, for the load line the following equation is valid:

$$
\frac{d p_{t}}{d t}=\frac{\beta}{V_{t}-\left(A_{c y l 1}-A_{c y l 2}\right) \cdot x_{c y l}} \cdot\left(Q_{2}-Q_{3}-Q_{4}\right) .
$$

The $Q_{1}$ and $\mathrm{Q}_{2}$ flow rates are determined using the piston rod equation of motion:

$$
\begin{gathered}
v_{c y l}=\frac{d x_{c y l}}{d t} \\
\frac{d v_{c y l}}{d t}=\frac{p_{s} \cdot A_{c y l 1}-p_{t}\left(A_{c y l 1}-A_{c y l 2}\right)-v_{c y l} \cdot \alpha_{c y l}-F_{l o a d}}{m_{c y l}}
\end{gathered}
$$

Having determined $v_{c y l}(t)$, the unknown flow rates can be calculated:

$$
\begin{gathered}
Q_{1}=v_{c y l} \cdot A_{c y l 1}, \\
Q_{2}=v_{c y l} \cdot\left(A_{c y l 1}-A_{c y l 2}\right) .
\end{gathered}
$$

The determination of $Q_{3}$ requires the equation of the differential valve poppet motion:

$$
\begin{gathered}
v_{3}=\frac{d x_{3}}{d t}, \\
\frac{d v_{3}}{d t}=\frac{\left(p_{t}-p_{s}\right) \cdot \frac{\pi D_{3}^{2}}{4}-v_{3} \cdot \alpha_{3}-k_{3} \cdot x_{3}-F_{s 3}}{m_{3}} .
\end{gathered}
$$

The range of the $x_{3}$ poppet movement is $05 \mathrm{~mm}$. The $Q_{3}(t)$ flow rate through the gap is calculated from Bernoulli's equation, assuming that $p_{t}(t) \geq p_{s}(t)$. Otherwise, $Q_{3}(t)=0$.

$$
Q_{3}=c_{3} \cdot A_{3} \cdot \sqrt{\frac{2\left(p_{t}-p_{s}\right)}{\rho}},
$$

where the $A_{3}(t)$ gap for a standard poppet version with a flat head has a ring shape of $D_{3}$ diameter (Fig. 2). Therefore, the gap area is:

$$
A_{3}=\pi \cdot D_{3} \cdot x_{3} .
$$

The $Q_{4}(t)$ throttle valve flow is calculated similarly to $Q_{3}(t)$, except that in this case the throttling gap has a fixed area, depending on the $x_{4}$ pin position. The gap area can be adjusted by the operator using the valve knob (Fig. 4). The equation is valid when the return line pressure is lower than the load line pressure: $p_{r e t}<p_{t}$.

$$
Q_{4}=c_{4} \cdot A_{4}\left(x_{4}\right) \cdot \sqrt{\frac{2\left(p_{t}-p_{r e t}\right)}{\rho}} .
$$

The $Q_{5}(t)$ flow rate through the relief valve is also based on a poppet position, whose equation of motion has the following form:

$$
v_{5}=\frac{d x_{5}}{d t},
$$

$$
\frac{d v_{5}}{d t}=\frac{\left(p_{s}-p_{r e t}\right) \frac{\pi D_{5}^{2}}{4}-v_{5} \cdot \alpha_{5}-k_{5} \cdot x_{5}-F_{s 5}}{m_{5}} .
$$

The $F_{s 5}$ initial spring tension provides opening of the valve when the pressure in the supply line exceeds $20 \mathrm{MPa}$. In this case, a cylindrical gap of $D_{5}$ diameter and $x_{5}$ width is formed. Hence, the flow rate can be calculated as:

$$
Q_{5}=c_{5} \cdot A_{5}(t) \cdot \sqrt{\frac{2\left(p_{s}-p_{r e t}\right)}{\rho}},
$$

where:

$$
A_{5}(t)=\pi \cdot D_{5} \cdot x_{5}(t)
$$

The presented system of 16 equations: Eqs. (2) to (17) fully describes the parameters of the analysed system. It allows the following timedependent parameters to be calculated: $p_{s}, p_{t}$ pressures, $Q_{p}, Q_{1}, \ldots, Q_{5}$ flow rates, $x_{c y l}, x_{3}, x_{5}$ positions, $v_{c y l}$, $v_{3}, v_{5}$ velocities, and $A_{3}, A_{5}$ gap areas. The presented equations were next used to build a simulation model in Matlab-Simulink.

\subsection{Building a Simulation Model}

A simulation model was created using a block diagram technique, which is default for research conducted in Simulink. Block diagram models of hydraulic systems were created and analysed, e.g. by Kuehnlein et al. 


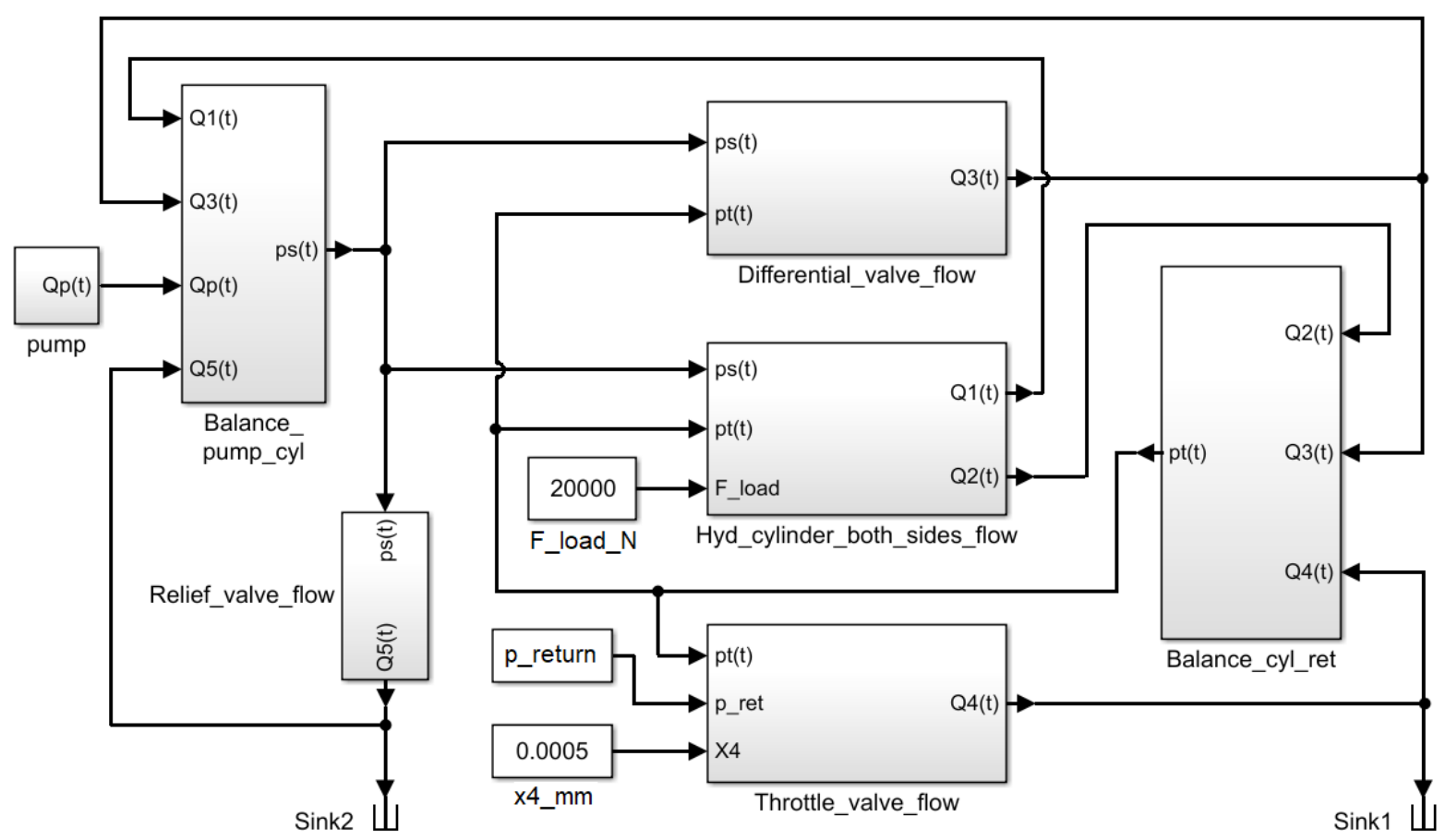

Fig. 6. Block diagram of the hydraulic system model

[12], Rybarczyk et al. [13], Milecki and Rybarczyk [14] and Muller and Fales [15]. The authors of this article also have experience in the analysis of hydraulic systems using block diagram models. This technique was used for modelling of a multi-section proportional directional control valve [16] and a proportional flow control valve [17]. A general view of the created simulation model is shown in Fig. 6.

Individual blocks represent the main hydraulic components, while the connectors indicate particular signals, such as pressures and flow rates. The $Q_{p}(t)$ input signal is a flow rate generated by the pump. First, the $p_{s}(t)$ supply line pressure is calculated in the Balance_pump_cyl subsystem. Then, the pressure signal is sent to the blocks representing hydraulic components, in order to determine flow rates: $Q_{1}(t), Q_{2}(t)$ in Hyd_cylinder_both_sides_flow, and respectively $Q_{3}(t)$ in Differential_valve_flow and $Q_{5}(t)$ in Relief_valve_flow. Flow rate values are next used to calculate the $p_{t}(t)$ load line pressure in the Balance_cyl_ret block. The pressure signal is directed to valve blocks, closing the system and allowing the $Q_{4}(t)$ throttle valve flow to be determined in the Throttle_valve_flow subsystem. There are also three parameters that can be updated by the user before the simulation starts. Values of the F_load_N payload force and the $\mathrm{x} 4$ mm throttle valve position may be entered directly by editing the block properties, while the return line pressure, which is used in multiple blocks, can be changed using a p_return system variable. The fluid temperature has been assumed to be approximately constant $(T=293 \pm 2 \mathrm{~K})$, which results in constant density and viscosity. Several significant geometric dimensions and parameters of the fluid adopted for the simulation model, which is hydraulic oil HL 46, are shown in Table 1.

Table 1. Values of simulation model parameters

\begin{tabular}{lccc}
\hline Name & Symbol & Value & Unit \\
\hline Cylinder diameter & $D_{c y l 1}$ & 60.0 & $\mathrm{~mm}$ \\
\hline Rod diameter & $D_{c y l 2}$ & 32.0 & $\mathrm{~mm}$ \\
\hline Rel. valve poppet diam. & $D_{5}$ & 12.0 & $\mathrm{~mm}$ \\
\hline Diff. valve poppet diam. & $D_{3}$ & 9.0 & $\mathrm{~mm}$ \\
\hline Fluid density & $\rho$ & 840 & $\mathrm{~kg} \cdot \mathrm{m}^{-3}$ \\
\hline Fluid kinematic viscosity & $v$ & 41 & $\mathrm{~mm}^{2} \cdot \mathrm{s}^{-1}$ \\
\hline Fluid bulk modulus & $\beta$ & 103 & $\mathrm{MPa}$ \\
\hline Nominal pump flow rate & $Q_{p}$ & 15.0 & $\mathrm{dm} \cdot \mathrm{min}^{-1}$ \\
\hline Relief valve pressure & $p_{5}$ & 20.0 & $\mathrm{MPa}$ \\
\hline Return line pressure & $p_{\text {ret }}$ & 0.1 & $\mathrm{MPa}$ \\
\hline
\end{tabular}

Simulations were carried out using a $4^{\text {th }}$ order, built-in, variable-step solver of Simulink. The values 
of the main configuration parameters are presented in Table 2.

Table 2. Solver configuration parameters

\begin{tabular}{lcc}
\hline Name & Value & Unit \\
\hline Solver name & ode45 & - \\
\hline Stop time (simulation length) & 10 & S \\
\hline Maximum step size & $10^{-4}$ & S \\
\hline Minimum step size & $10^{-7}$ & S \\
\hline Initial step size & $10^{-4}$ & S \\
\hline Relative tolerance & $10^{-4}$ & - \\
\hline Absolute tolerance & Auto & - \\
\hline
\end{tabular}

In general, the research was aimed at estimating the piston rod speed as a function of the throttle valve gap width and the payload force. Therefore, the simulations have been conducted for the Cartesian product of the following throttle gap widths: $x_{4}=(0.00,0.25,0.50,0.75,1.00,1.50,2.00,3.00) \mathrm{mm}$ and the payload force of: $F_{\text {load }}=(1.0,5.0,10.0,12.8$, $20.0,30.0) \mathrm{kN}$.

\section{SIMULATION RESULTS}

Example simulation results obtained with a fixed position of the throttle valve pin $x_{4}=1.00 \mathrm{~mm}$ for different $F_{\text {load }}=1.0 \mathrm{kN}$ and $F_{\text {load }}=20.0 \mathrm{kN}$ payload force values are shown in Figs. 7 and 8, respectively. The results include $x_{c y l}(t)$ piston rod displacement against time and the following flow rate values: a $Q_{1}(t)$ hydraulic cylinder inflow rate, a $Q_{3}(\mathrm{t})$ differential valve flow rate and a $Q_{4}(\mathrm{t})$ throttle valve flow rate. It arises from the charts that in the case when the payload force is low (Fig. 7), additional stream $Q_{3}$ from the return line gives a considerable increase in the piston rod speed. In contrast, if the payload force is higher than a threshold value (Fig. 8), the flow through the differential valve is cut off $\left(Q_{3}=0\right)$ and the rod speed is more than two times lower.

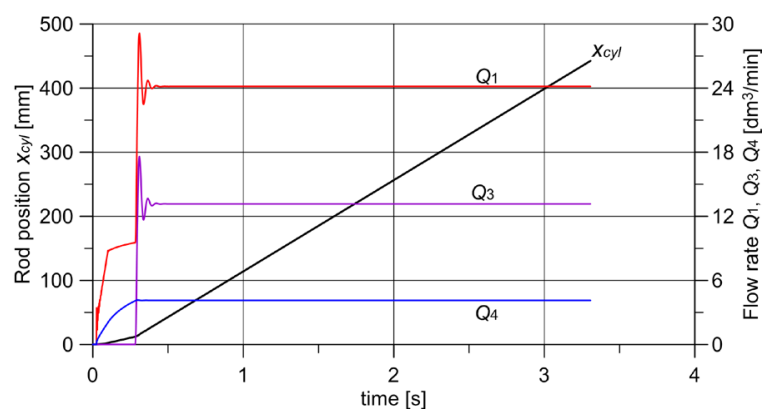

Fig. 7. Simulation results obtained for $x_{4}=1.0 \mathrm{~mm}$ and $F_{\text {load }}=1.0 \mathrm{kN} ; x_{c y l}$ piston rod displacement; $Q_{1}, Q_{3}, Q_{4}$ flow rate

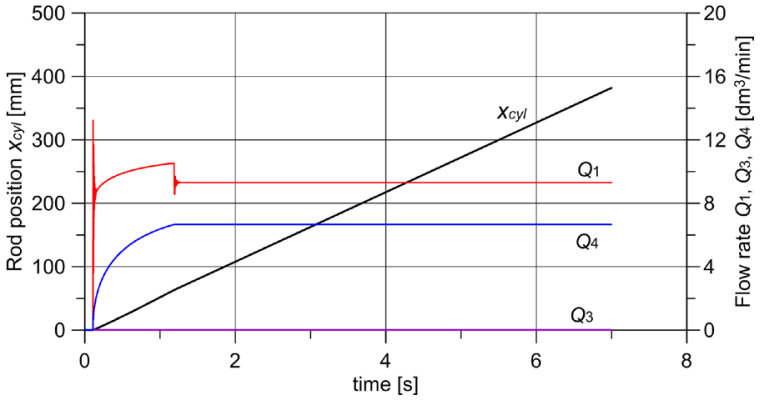

Fig. 8. Simulation results obtained for $x_{4}=1.0 \mathrm{~mm}$ and $F_{\text {load }}=20 \mathrm{kN} ; x_{\text {cyl }}$ piston rod displacement; $Q_{1}, Q_{3}, Q_{4}$ flow rate

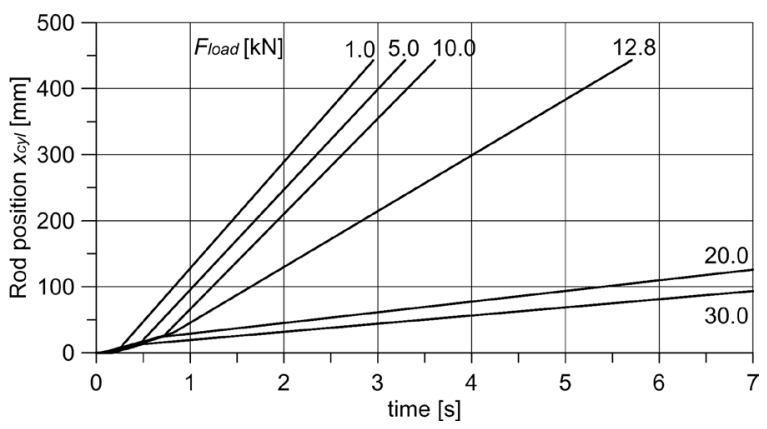

Fig. 9. Piston rod displacement (simulation); $x_{4}=0.5 \mathrm{~mm} ; F_{\text {load }}$ payload force

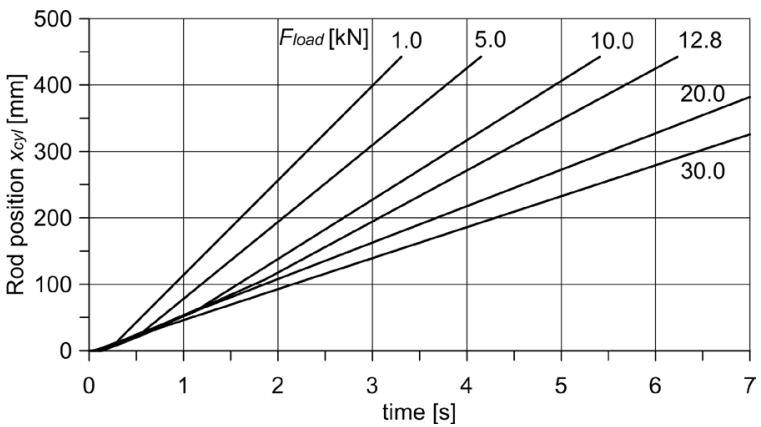

Fig. 10. Piston rod displacement (simulation); $x_{4}=1.0 \mathrm{~mm}$; $F_{\text {load }}$ payload force

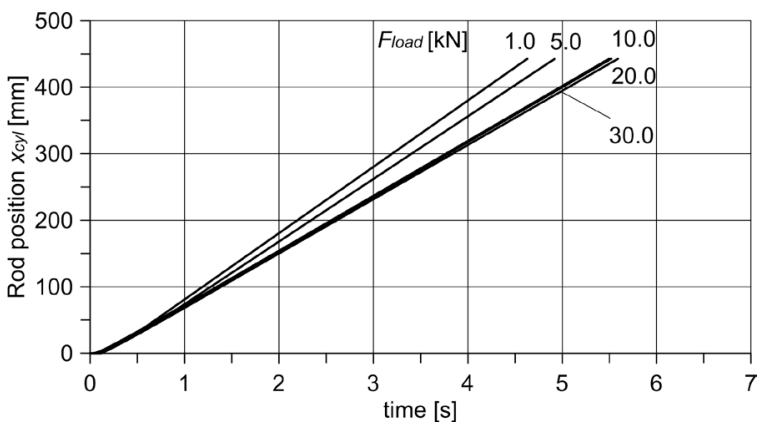

Fig. 11. Piston rod displacement (simulation); $x_{4}=1.5 \mathrm{~mm}$; $F_{\text {load }}$ payload force 
Figs. 9 to 11 show summary charts of the piston rod displacement obtained for the following values of the throttling gap width of $x_{4}=0.5 \mathrm{~mm}, x_{4}=1.0 \mathrm{~mm}$ and $x_{4}=1.5 \mathrm{~mm}$, respectively, while the $v_{c y l}=f\left(x_{4}\right.$, $\left.F_{\text {load }}\right)$ resultant surface created on the basis of the values is shown in Fig. 12. As seen in the figures, if the gap width is relatively small $\left(x_{4}=0.5 \mathrm{~mm}\right)$, the speed of the cylinder rod which depends on the payload force, shows a clear division into two areas. The simulations allowed a threshold value to be determined, which was $F_{\text {load }}=12.8 \mathrm{kN}$. For $F_{\text {load }} \leq 10 \mathrm{kN}$, the hydraulic actuator rod reaches the speed of $v_{c y l}=120 \mathrm{~mm} \mathrm{~s}^{-1}$ to $150 \mathrm{~mm} \mathrm{~s}^{-1}$. In contrast, when $F_{\text {load }} \geq 20 \mathrm{kN}$, the speed decreases dramatically to the value of $v_{c y l}<20 \mathrm{~mm} \mathrm{~s}^{-1}$.

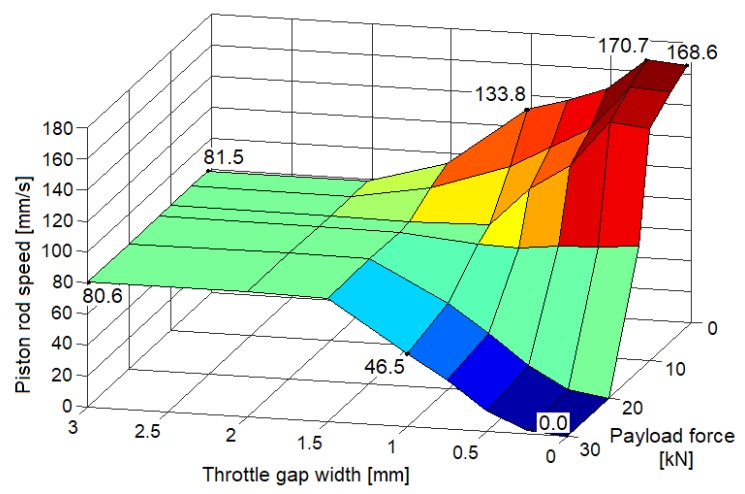

Fig. 12. Piston rod speed against gap width $x_{4}$ and payload force $F_{\text {load }}$ (simulation)

The increase in the throttling gap width makes the range of hydraulic cylinder rod speed change to be significantly reduced. However, the speed obtained for the threshold value of the payload is similar, regardless of the gap width of $v_{c y l}=75.9 \mathrm{~mm} \mathrm{~s}^{-1}$ for $x_{4}=1.0 \mathrm{~mm}$ and $v_{c y l}=80.4 \mathrm{~mm} \mathrm{~s}^{-1}$ for $x_{4}=1.5 \mathrm{~mm}$. The results also indicate that the difference in the piston rod speed for $x_{4} \geq 2.0 \mathrm{~mm}$ is negligible. The average values of the piston rod speed are presented in Table 3.

Table 3. Piston rod speed vcyl against $x_{4}$ and $F_{\text {load }}$ (simulation)

\begin{tabular}{ccccccccc}
\hline & \multicolumn{8}{c}{$x_{4}[\mathrm{~mm}]$} \\
\cline { 2 - 9 } & 0.00 & 0.25 & 0.50 & 0.75 & 1.00 & 1.50 & 2.00 & 3.00 \\
\hline 1.0 & 168.6 & 170.7 & 150.0 & 141.1 & 133.8 & 95.6 & 81.3 & 81.5 \\
\hline 5.0 & 161.3 & 162.8 & 134.6 & 121.1 & 106.7 & 90.0 & 81.2 & 81.5 \\
\hline 10.0 & 149.9 & 152.6 & 122.6 & 106.2 & 81.8 & 80.5 & 81.0 & 81.3 \\
\hline 12.8 & 81.1 & 78.5 & 77.6 & 75.1 & 75.9 & 80.4 & 80.9 & 81.2 \\
\hline 20.0 & 0 & 3.7 & 18.0 & 36.9 & 54.6 & 80.2 & 80.7 & 81.0 \\
\hline 30.0 & 0 & 2.0 & 13.3 & 31.4 & 46.5 & 79.2 & 80.3 & 80.6 \\
\hline
\end{tabular}

\section{TEST BENCH EXPERIMENTS}

The results of simulations were verified on a test bench using a prototype of the valve. The test bench has been built according to the schematic shown in Fig. 13.

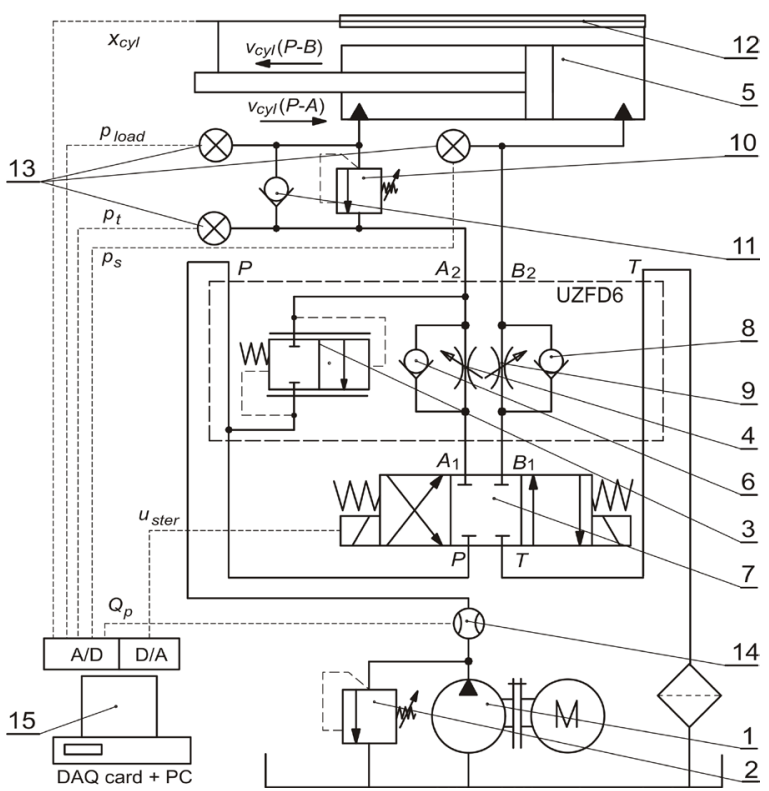

Fig. 13. Test bench schematic: (1) pump, (2), (10) relief valve, (3) differential valve, (4), (9) throttle valve, (5) hydraulic actuator, (6), (8), (11) check valve, (7) control valve, (12) LVDT transducer, (13) pressure transducers, (14) flow meter, (15) DAQ card and PC

The supply unit includes a pump (1) and a relief valve (2). The UZFD6 prototype valve consists of a differential valve (3), two check valves (6), (8) and two adjustable throttle valves (4), (9). The UZFD6 valve is rigidly connected to the control valve (7), which provides flow continuity through the $P$ supply port, the $T$ return port, and the $A_{1}-A_{2}, B_{1}-B_{2}$ operating ports. Depending on the $u_{\text {ster }}$ control valve settings, the right or left side of a hydraulic cylinder (5) is supplied. When the piston rod is sliding out $\left(P-B_{1}\right)$, the payload force is generated by a pressure relief valve (10). Otherwise $\left(P-A_{1}\right)$, the fluid flows through the check valve (11). A manually operated VS350 Parker valve was used as a payload generator. Flow characteristics of the valve are shown in Fig. 14.

All input and output signals are managed by a NI PCIe-6321 card with a SCB-68A wiring terminal. The following parameters are measured and acquired during the experiments: $Q=Q_{p}-Q_{5}$ supply flow rate (14), $x_{c y l}$ rod displacement (12), and pressures, respectively $p_{s}$ in the supply line, $p_{\text {load }}$ in the load line and $p_{t}$ in the return line (13). The $u_{\text {ster }}$ signal allows an 
operator to change the control valve (7) setting during the experiment. A general view of the test bench is shown in Fig. 15, and the valve prototype can be seen in Fig. 16.

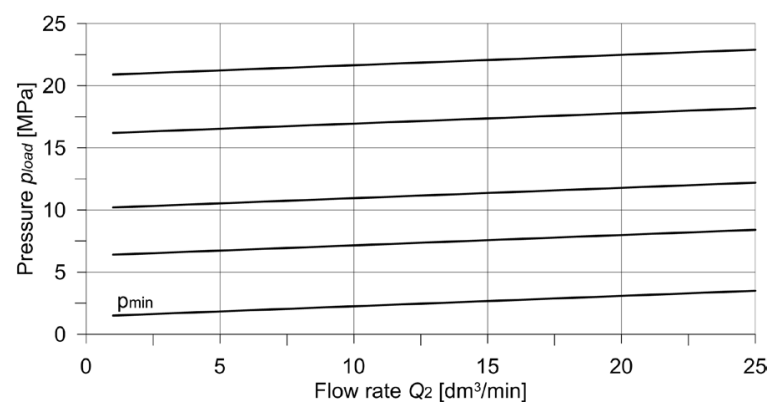

Fig. 14. Relief valve flow characteristics

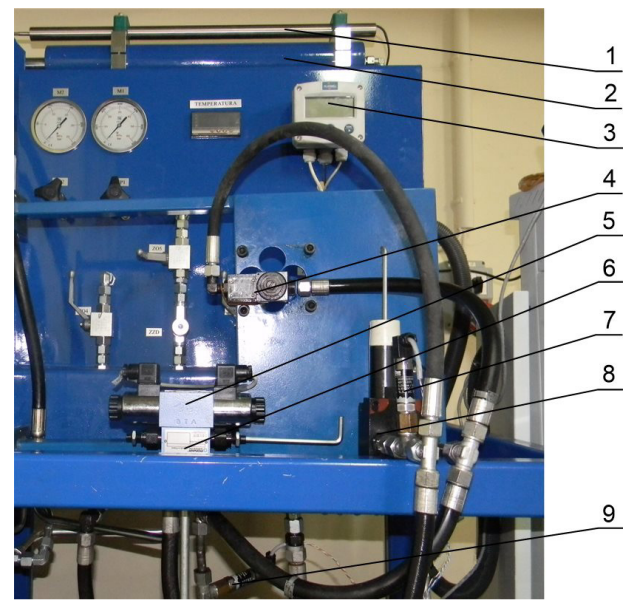

Fig. 15. Test bench view: (1) LVDT transducer, (2) hydraulic actuator, (3) flow rate gauge, (4) check valve, (5) control valve, (6) UZFD6 valve, (7), (9) pressure transducer, (8) payload generating relief valve

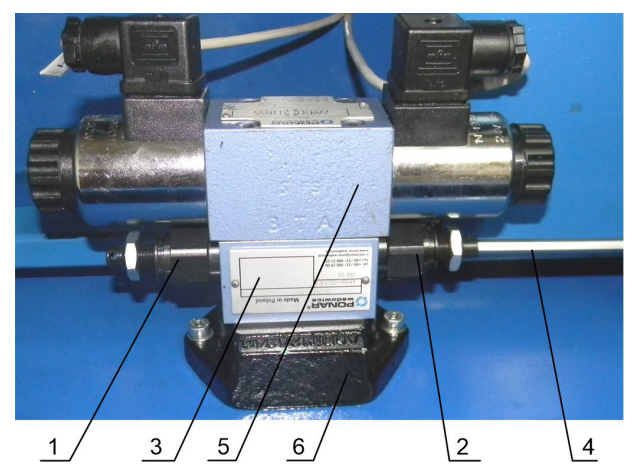

Fig. 16. The studied valve at the test bench: (1), (2) throttle valve knob, (3) UZFD6 valve, (4) handle, (5) control valve, (6) mounting plate

Before each laboratory test, the piston rod is set to $x_{c y l}=0.0 \mathrm{~mm}$. Next, the $p_{\text {load }}$ load line pressure and the $x_{4}$ throttle valve gap width are set by means of knobs of the relief valve and the throttle valve. The power supply is turned on, the control valve is set to the $P-B_{1}$ position, and the rod moves out. After reaching the maximum extension, an operator sets the control valve to the $P-A_{1}$ position, and the rod moves in the opposite direction, returning to the starting position.

The actual value of the payload force can be calculated basing on the difference between the load line pressure and the return line pressure:

$$
F_{\text {load }}=\frac{\pi}{4}\left(D_{c y l 1}^{2}-D_{c y l 2}^{2}\right) \cdot\left(p_{\text {load }}-p_{t}\right) .
$$

Example results of the laboratory tests obtained with a fixed position of the throttle valve pin $x_{4}=1.0 \mathrm{~mm}$ for different values of the payload force of $F_{\text {load }}=1.53 \mathrm{kN}$ and $F_{\text {load }}=19.11 \mathrm{kN}$ are shown in Figs. 17 and 18, while the summary charts are presented in Figs. 19 to 21.

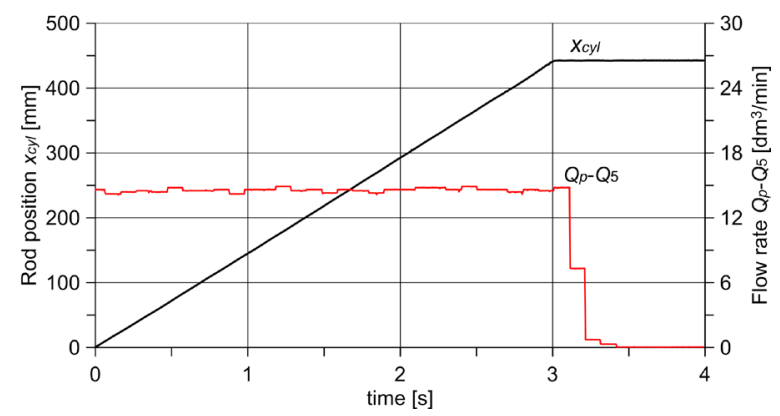

Fig. 17. Laboratory results obtained for $x_{4}=1.0 \mathrm{~mm}$ and $F_{\text {load }}=1.53 \mathrm{kN} ; x_{\text {cyl }}$ piston rod displacement; $Q_{p}-Q_{5}$ supply flow rate

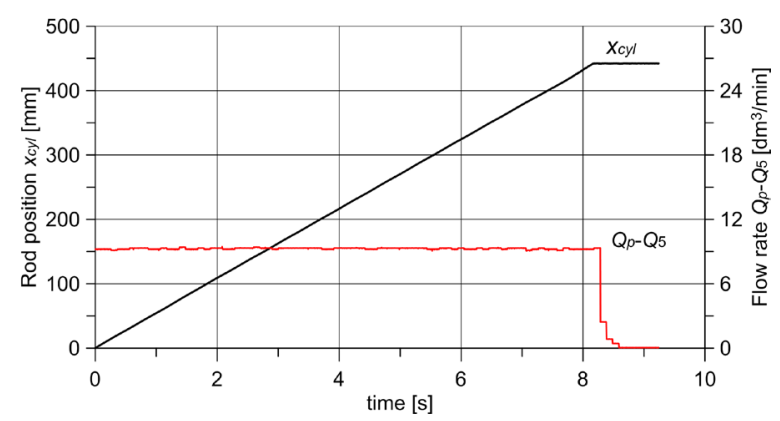

Fig. 18. Laboratory results obtained for $x_{4}=1.0 \mathrm{~mm}$ and $F_{\text {load }}=19.11 \mathrm{kN} ; x_{\text {cyl }}$ piston rod displacement; $Q_{p}-Q_{5}$ supply flow rate

As seen in Figs. 17 and 18, the end position of the piston rod was achieved after $3.0 \mathrm{~s}$ in the case of the payload force of $F_{\text {load }}=1.53 \mathrm{kN}$, and after $8.1 \mathrm{~s}$ for $F_{\text {load }}=19.1 \mathrm{kN}$. Thus, the speed was decreased by 2.7 times. 


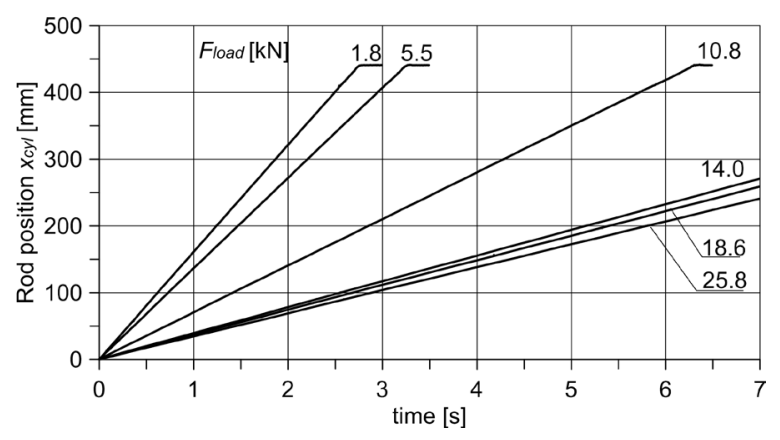

Fig. 19. Piston rod displacement (experiment); $x_{4}=0.5 \mathrm{~mm} ; F_{\text {load }}$ payload force

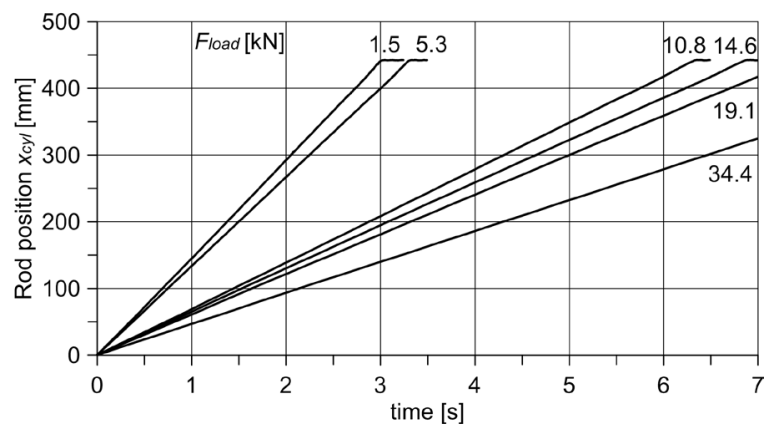

Fig. 20. Piston rod displacement (experiment); $x_{4}=1.0 \mathrm{~mm} ; F_{\text {load }}$ payload force

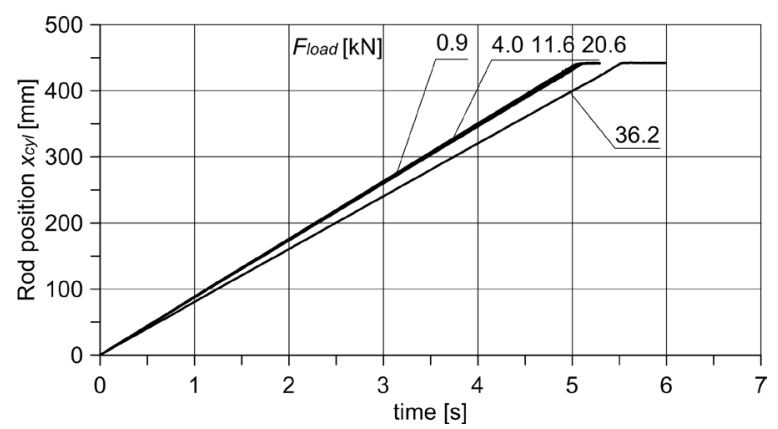

Fig. 21. Piston rod displacement (experiment); $x_{4}=1.5 \mathrm{~mm} ; F_{\text {load }}$ payload force
The average values of the piston rod speed obtained during the test bench experiments are presented in Table 4. It was taken into account that, unlike simulations, the actual payload force values for individual tests were not exactly the same. A resultant surface of $v_{c y l}=f\left(x_{4}, F_{\text {load }}\right)$ based on the experimental piston rod speed values is shown in Fig. 22.

The comparison of simulation results (Figs. 7 to 12, Table 3) with the laboratory experiments (Figs. 17 to 22, Table 4) show a high degree of convergence. In both cases, the obtained values of piston rod speed are close. Furthermore, a clear difference in piston rod speed that depends on the payload force can be observed.

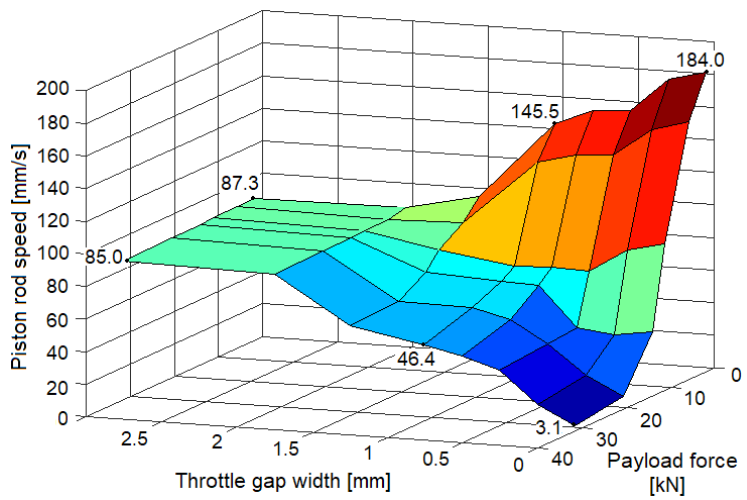

Fig. 22. Piston rod speed against gap width $x_{4}$ and payload force $F_{\text {load }}$ (experiment)

\section{SUMMARY}

This article provides an analysis of an innovative valve that uses the energy of a return fluid stream from a hydraulic actuator to increase the piston rod speed of movement. At the beginning, a mathematical model was formulated. Next, piston rod speed was determined for various variants of the payload

Table 4. Piston rod speed $v_{\text {cyl }}$ against $x_{4}$ and $F_{\text {load }}$ (experiment)

\begin{tabular}{lcccccccc}
\hline & \multicolumn{7}{c}{$x_{4}[\mathrm{~mm}]$} & \\
\cline { 2 - 10 } & 0.00 & 0.25 & 0.50 & 0.75 & 1.00 & 1.50 & 2.00 & 3.00 \\
\hline$F_{\text {load }}[\mathrm{kN}]$ & 3.6 & 3.4 & 2.8 & 2.7 & 5.4 & 1.0 & 0.9 & 1.0 \\
\hline$v_{c v l}\left[\mathrm{~mm} \cdot \mathrm{s}^{-1}\right]$ & 184.0 & 177.8 & 156.9 & 158.6 & 126.8 & 87.9 & 87.6 & 87.3 \\
\hline$F_{\text {load }}[\mathrm{kN}]$ & 6.1 & 5.9 & 5.5 & 5.7 & 10.8 & 4.0 & 4.0 & 4.1 \\
\hline$v_{c y l}\left[\mathrm{~mm} \cdot \mathrm{s}^{-1}\right]$ & 157.8 & 151.7 & 134.7 & 143.0 & 69.7 & 86.5 & 85.2 & 86.6 \\
\hline$F_{\text {load }}[\mathrm{kN}]$ & 11.3 & 11.1 & 10.8 & 11.0 & 14.6 & 11.6 & 11.2 & 11.7 \\
\hline$v_{\text {cyl }}\left[\mathrm{mm} \cdot \mathrm{s}^{-1}\right]$ & 89.5 & 84.2 & 70.0 & 77.6 & 64.2 & 86.5 & 84.8 & 86.8 \\
\hline$F_{\text {load }}[\mathrm{kN}]$ & 14.0 & 18.8 & 18.6 & 26.5 & 19.1 & 20.6 & 20.6 & 20.9 \\
\hline$v_{c y l}\left[\mathrm{~mm} \cdot \mathrm{s}^{-1}\right]$ & 39.3 & 19.3 & 36.9 & 51.1 & 56.1 & 86.2 & 83.6 & 85.0 \\
\hline
\end{tabular}


force and the flow rate through the throttling valve using Matlab-Simulink. To validate the results of the theoretical analysis, a test bench was built. The laboratory tests carried out at the bench were analogous to those conducted during simulations. The obtained experimental results confirmed that redirecting the return flow from the actuator to the supply line can more than double the movement speed of the piston rod operating at low load. In general, the proposed solution is advantageous, since it provides significant shortening of the operating time due to the speed increase without the need to install a more efficient pump and thus not only reduces energy demands but is also cost-effective. Compared to the commonly used direct connection between the supply line and the return line, the proposed solution is more adjustable. In addition to the speed increase, it also provides speed reduction under large load and, due to the sandwich type connection port arrangement, it can be easily installed in existing systems without the need to use additional equipment.

\section{REFERENCES}

[1] Lin, T., Wang, L., Huang, W., Ren, H., Fu, S., Chen, Q. (2017). Performance analysis of an automatic idle speed control system with a hydraulic accumulator for pure electric construction machinery. Automation in Construction, vol. 84, p. 184-194, D0I:10.1016/j.autcon.2017.09.001.

[2] Perez, J.A.L., De Pieri, E.R., De Negri, V.J. (2018). Force control of hydraulic actuators using additional hydraulic compliance. Strojniški vestnik - Journal of Mechanical Engineering, vol. 64, no. 10, p. 579-589, D0l:10.5545/sv-jme.2018.5339.

[3] Wang, J., Sun, Y., Huang, X., Li, Z., Han, Y. (2015). Research on the position-pressure master-slave control for a rolling shear hydraulic servo system. Strojniški vestnik - Journal of Mechanical Engineering, vol. 61, no. 4, p. 265-272, DOl:10.5545/sv-jme.2014.2291.

[4] Wang, W., Wang, B. (2016). An energy-saving control strategy with load sensing for electro-hydraulic servo systems. Strojniški vestnik - Journal of Mechanical Engineering, vol. 62, no. 12, p. 709-716, Dol:10.5545/sv-jme.2016.3685.

[5] Liu, J., Xie, H., Hu, L., Yang, H., Fu, X. (2017). Realization of direct flow control with load pressure compensation on a load control valve applied in overrunning load hydraulic systems. Flow Measurement and Instrumentation, vol. 53, p. 261-268, D0I:10.1016/j.flowmeasinst.2016.07.004.

[6] Adeoye, A.O.M., Aderoba, A.A., Oladapo, B.I. (2017). Simulated design of a flow control valve for stroke speed adjustment of hydraulic power of robotic lifting device. Procedia Engineering, vol. 173, p. 1499-1506, D0l:10.1016/j.proeng.2016.12.230.

[7] Xie, H., Liu, J., Hu, L., Yang, H., Fu, X. (2015). Design of pilotassisted load control valve for proportional flow control and fast opening performance based on dynamics modeling. Sensors and Actuators A: Physical, vol. 235, p. 95-104, DOI:10.1016/j.sna.2015.09.042.

[8] Man, Z., Ding, F., Ding, C., Liu, S. (2015). Study of an energy regeneration system with accumulator for hydraulic impulse testing equipment. Strojniški vestnik - Journal of Mechanical Engineering, vol. 61, no. 3, p. 196-206, D0l:10.5545/svjme.2014.2138.

[9] Watton, J., Nelson, R.J. (1993). Evaluation of an electrohydraulic forge valve behavior using a CAD package. Applied Mathematical Modelling, vol. 17, no. 7, p. 355-368, DOI:10.1016/0307-904X(93)90060-T.

[10] Naseradinmousavi, P., Nataraj, C. (2011). Nonlinear mathematical modeling of butterfly valves driven by solenoid actuators. Applied Mathematical Modelling, vol. 35, no. 5, p. 2324-2335, DOI:10.1016/j.apm.2010.11.036.

[11] Casoli, P., Pompini, N., Riccò, L. (2015). Simulation of an excavator hydraulic system using nonlinear mathematical models. Strojniški vestnik - Journal of Mechanical Engineering, vol. 61, no. 10, p. 583-593, D0l:10.5545/sv-jme.2015.2570.

[12] Kuehnlein, M., Liermann, M., Ewald, J., Murrenhoff, H. (2012). Adjustable flow-control valve for the self-energising electrohydraulic brake. International Journal of Fluid Power, vol. 13, no. 2, p. 5-14, DOl:10.1080/14399776.2012.10781049.

[13] Rybarczyk, D., Sędziak, D., Owczarek, P., Owczarkowski, A. (2015). Modelling of electrohydraulic drive with a valve controlled by synchronous motor. In: Szewczyk R., Zieliński C., Kaliczyńska M. (eds.) Progress in Automation, Robotics and Measuring Techniques. Advances in Intelligent Systems and Computing, vol. 350, p. 215-222, D0l:10.1007/978-3-31915796-2_22.

[14] Milecki, A., Rybarczyk, D. (2015). Modelling of an electrohydraulic proportional valve with a synchronous motor. Strojniški vestnik - Journal of Mechanical Engineering, vol. 61, no. 9, p. 517-522, Dol:10.5545/sv-jme.2015.2553.

[15] Muller, M.T., Fales, R.C. (2008). Design and analysis of a twostage poppet valve for flow control. International Journal of Fluid Power, vol. 9, no. 1, p.17-26, Dol:10.1080/14399776.2 008.10781293.

[16] Lisowski, E., Filo, G., Rajda, J. (2015). Pressure compensation using flow forces in a multi-section proportional directional control valve. Energy Conversion and Management, vol. 103, p. 1052-1064, DOI:10.1016/J.enconman.2015.07.038.

[17] Lisowski, E., Filo, G. (2016). CFD analysis of the characteristics of a proportional flow control valve with an innovative opening shape. Energy Conversion and Management, vol. 123, p. 1528, DOI:10.1016/J.enconman.2016.06.025. 